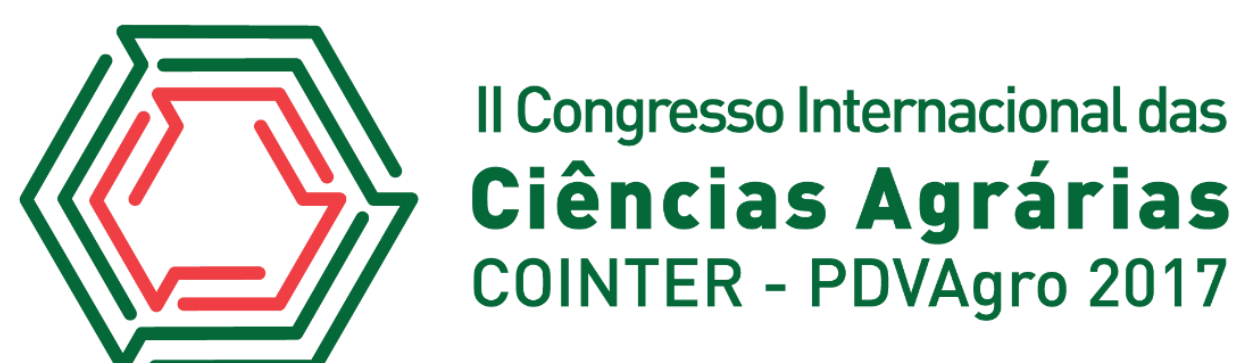

\title{
LEVANTAMENTO DE DADOS SOBRE AGRICULTURORES DE SÃO RAIMUNDO DAS MANGABEIRAS -MA
}

Apresentação: Pôster

João Verissimo Batista Neto ${ }^{1}$; Debora Janine Silva Gonçalves ${ }^{2}$; Márcio da Silva Vilela ${ }^{3}$

\section{Introdução}

O gigantesco desenvolvimento dos grandes centros urbanos trouxe consigo vários problemas, dentre os quais, a falta da ampliação da oferta de produtos e serviços para atender a demanda. Passou-se, consequentemente, a denotar a importância em investir em regiões mais afastadas, dos territórios metropolitanos e desenvolvidas.

A identificação das características gerais das propriedades, do manejo do solo e das pastagens, e da suplementação mineral constituem fatores determinantes para estabelecer índices produtivos, caracterizar fatores responsáveis pela menor produtividade e estabelecer medidas a serem recomendadas e adotadas pelos produtores visando aumento da produtividade com maior sustentabilidade (MINERVINO et al., 2008).

A sensibilização e conscientização sobre a importância de inovar disseminando informações para os agentes transformadores, instituições financeiras, de ensino, pesquisa e extensão, enfatizando benefícios do aprendizado interativo e da geração de ideias (LEMOS, 2002). Neste sentido o presente trabalho teve como objetivo apontar características da pecuária no município.

\section{Fundamentação Teórica}

Ao longo das últimas décadas as diversas mudanças ocorridas na economia mundial resultaram em impactos, tanto positivos quanto negativos, no desenvolvimento do setor agrícola, sobretudo modificando as estruturas produtivas das propriedades e as dinâmicas das

\footnotetext{
${ }^{1}$ Agronomia, Instituto Federal de Educação, Ciência e Tecnologia do Maranhão, verissimo316@gmail.com

${ }^{2}$ Agronomia, Instituto Federal de Educação, Ciência e Tecnologia do Maranhão, deboragoncalves94@gmail.com

${ }^{3}$ Doutor, Instituto Federal de Educação, Ciência e Tecnologia do Maranhão, vilela.marcio@ifma.edu.br
} 
famílias residentes no meio rural (BEZZUTI, 2011). Assim, é importante destacar o abismo que formou-se; agricultores com tecnologia e agricultores que não a possuem.

A pecuária expandiu a sua produção no mundo todo devido à grande importância da produção de proteína animal para a alimentação humana. O Brasil, devido a sua grande extensão de terras, apoio do governo na produção e riquezas naturais propícias tem a atividade pecuária bem desenvolvida (GONÇALVES, 2010). No entanto está não é a realidade de muitos municípios brasileiros. Neste sentindo é interessante estudar as particularidades e potenciais de municípios não tão destacados economicamente.

Nos últimos anos o advento da tecnologia nos ambientes empresariais tem se tornado constante. Devido à sua incrível capacidade de reduzir custos, a tecnologia ganhou legitimidade, e não se tornou essencial somente nas indústrias, mas também na sociedade, de modo que o modelo de vida atual é sustentado pelas descobertas vindouras das tecnologias. Diante desse contexto, que engloba todos os setores da economia, está a agricultura familiar. Essa, por ser de famílias geralmente de baixa renda, possui na maioria das situações pouco desenvolvimento tecnológico. E, além disso, a maioria desses produtores tem dificuldades de se adequar ao avanço da tecnologia (PICCHI; ZANIBONI, 2010). A tecnologia atualmente é um fator decisivo para qualquer atividade, não sendo diferente com a pecuária, identificar o nível tecnológico pode ser uma ferramenta para indicar o potencial produtivo de uma região.

\section{Metodologia}

São Raimundo das Mangabeiras se localiza na porção sul do Estado do Maranhão mais exatamente na Mesorregião Chapada das Mangabeiras na latitude $07^{\circ} 01^{\prime} 19^{\prime}$ 'S e longitude de $45^{\circ} 28^{\prime} 51^{\prime}$ 'W. Região de Bioma Cerrado, ocupando uma área de $3.522 \mathrm{~km}^{2}$. O município possui população de 17.480 pessoas (IBGE, 2010).

Foi realizada uma pesquisa do gênero qualitativo e quantitativo entre produtores rurais de diversas comunidades rurais, total de 37 questionários. Foram levantados dados da atividade pecuária, socioeconômico, níveis de instrução técnica e escolaridade da população rural do município de São Raimundo das Mangabeiras - MA, procurando descrevê-los, classificá-los e interpretá-los. Os dados obtidos foram processados através de Planilhas Base de Dados desenvolvidas no Excel 2016, do programa do pacote Office Microsoft@. 


\section{Resultados e Discussões}

Foram entrevistados produtores das seguintes comunidades: Buriti de dentro, Santa Isabel, Povoado Periquito, Samambaia, Povoado Brás, Assentamento Bacuri, Povoado Morro do Chupé, Povoado Canto Grande, Assaré, Santo Antônio e o Povoado Descanso. Todas estas comunidades se encontram próximas, as estradas encontram-se em bom estado, viabilizando o transporte e redução de custos. Segundo Cassiolato e Lastres (2001) devemos ver localização como um dos motivos para o bom desempenho e competitividade de empreendedores.

Cerca de $\pm 62 \%$ (considerando a soma das faixas de idade entre 18-39 e 40-60) da população rural do município e considerada economicamente ativa (Gráfico 1). Poucos entrevistados tinham trabalhadores não familiares em suas propriedades, com isto, caracterizando agricultura familiar. Os proprietários não dispõem de muitos equipamentos que venham auxiliar a as atividades de produção. Os equipamentos mais utilizados são a plantadeira manual $(70 \%)$ e o pulverizador costal (64\%). Este fato implica na redução de sua produção, pois em diversos casos eles possuem uma quantidade considerável de terras para as criações de animais ou cultivo, mas não conseguem explorar de forma eficaz por não poderem pagar mão de obra ou investir em equipamentos e insumos. Esta situação é explicada pela baixa renda, grande parte dos produtores sobrevive apenas com o cultivo do Feijão e ou produção de Leite, juntamente com programas sociais como a Bolsa família.

Gráfico 1: Utilização de insumos. Fonte Própria

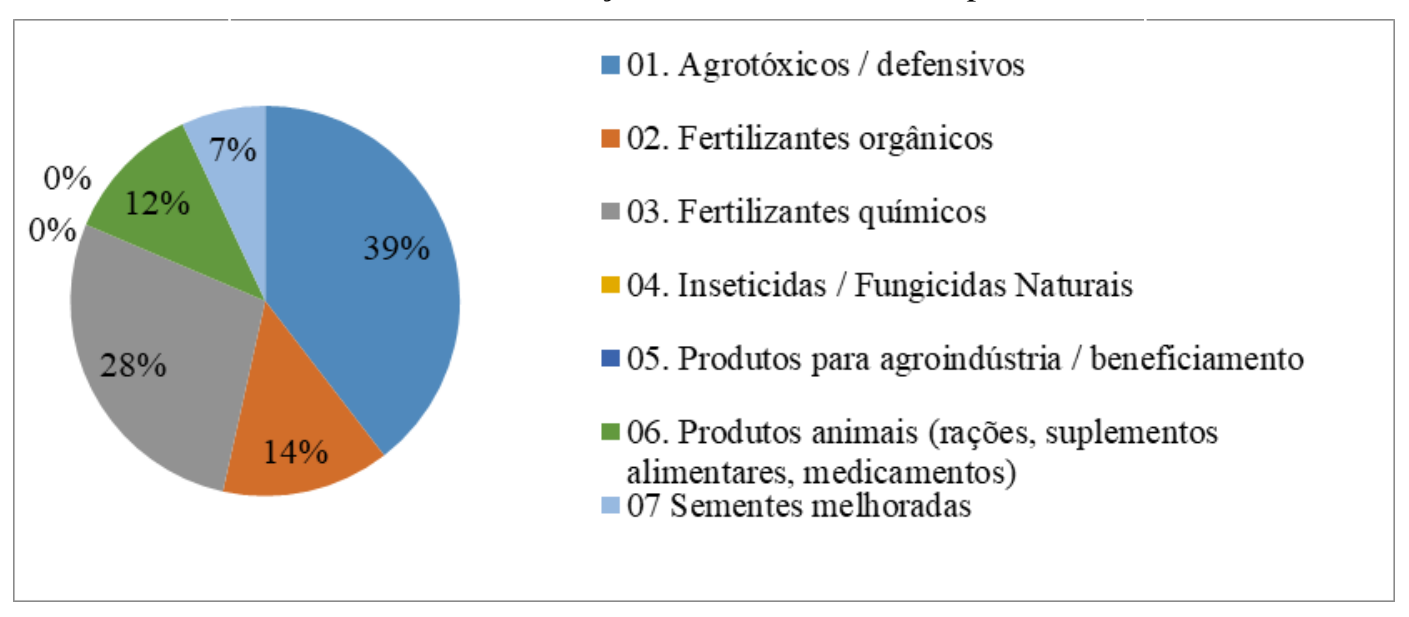

Como pode-se observar (Gráfico 1) a utilização de insumos aos animais é pequena. As espécies mais exploradas são: bovina, suína e a aves, criados sistema extensivo, ou seja, criações de subsistência. Para bom desempenho produtivo, os animais requerem alimentação 
balanceada para melhor expressão do potencial genético, de acordo com cada espécie. Normalmente os suínos e as aves exploradas, são alimentados com resto de comida e medicados sem acompanhamento especializado, prejudicando a saúde dos animais, seu desempenho produtivo.

Aproximadamente $86 \%$ dos entrevistados afirmaram não possuir assistência técnica. No município é difícil o acesso aos programas de assistência técnica gratuita via (prefeitura e sindicato) e os produtores não possuem a condição necessária para contratar assistência técnica autônoma. Segundo os produtores que possuem assistência, o serviço é fornecido de forma irregular.

Segundo Franco (2010) é de suma importância o papel que exerce a difusão e transferência tecnológica na agricultura familiar. Normalmente, quando o produtor rural encontra-se desassistido da extensão rural, é notório o desagregamento dos cultivos praticados por cada um, manifestando um desconhecimento total. De outra forma, quando o mesmo, procura ou integra-se ao sistema de extensão rural, é visível a melhoria, tanto das culturas plantadas, assim como do padrão de vida.

De acordo com Pfüller et al. (2007), nesta realidade, o proprietário não é conhecedor de seu próprio negócio, perdendo oportunidades ou colocando sua atividade e sua propriedade em risco quando, por exemplo, não aproveita as potencialidades, não comercializa seus produtos no momento certo, ou não tem posse das informações que mostram se as atividades desenvolvidas na propriedade são rentáveis e se estas são as mais recomendadas para sua realidade. É mediante resultados econômicos que o produtor pode tomar, conscientemente, suas decisões (LOPES; CARVALHO, 2002)

\section{Conclusões}

A população rural do município mais especificamente os pecuaristas necessitam de apoio e reformas políticas, técnicas e social. As principais dificuldades encontradas foram: acesso ao crédito, gerenciamento da propriedade, falta de capacitação, falta de assistência técnica, escoamento da produção (comercialização, pois não há valorização do comercio local).

\section{Referências}


BEZZUTI, H.; FILHO, L. F. F.; FRITZ, K. B. B. A Agricultura familiar no município de Água Santa -RS: um estudo de caso dos indicadores agropecuários, estratégias de diversificação e autoconsumo em duas unidades de produção. Revista IDeAS, v. 5, n. 1, p. 116-159, 2011.

BRASIL. IBGE. Instituto Brasileiro de Geografia e Estatística. 2010

CASSIOLATO, J. E.; LASTRES, H. M. M. Arranjos e sistemas produtivos locais na indústria brasileira. Revista de economia contemporânea, v. 5, p. 103-136, 2001.

FRANCO, C. F. O. Dinâmica da difusão de tecnologia no sistema produtivo da agricultura $\quad$ brasileira. $2010 . \quad$ Disponível <http://www.emepa.org.br/anais/volume2/av210.pdf.>. Acessado em: 15/09/2017.

GONÇALVES, F. P. P. Viabilidade econômica da produção de bovinos de corte a pasto: estudo de caso em uma fazenda do município de juina - MT. Curitiba, 2010. Disponível em: $<$ http://acervodigital.ufpr.br/bitstream/handle/1884/39303/R\%20-

$\%$ 20E\% 20\%20FLAVIO\%20PERUZO\%20PIRES\%20GONCALVES.pdf?sequence=2 $>$.

Acessado em: 15/09/2017.

LEMOS, C. Interagir para competir: promoção de arranjos produtivos e inovativos no Brasil. SEBRAE: FINEP: CNPq, p. 95-134, Brasília, 2002.

LOPES, M. A.; CARVALHO, F.M. Custo de produção do gado de corte. Lavras: UFLA, 2002. 47p. (Boletim Agropecuário, 47).

MINERVINO, A. H. H. et al. Características do sistema produtivo da pecuária no município de Santarém, Pará. ACTA AMAZONICA, vol. 38(1) 2008: 11 - 16. Disponível em: < http://www.scielo.br/pdf/aa/v38n1/v38n1a03.pdf> . Acessado em: 15/09/2017.

PICCHI, M. R.; ZANIBONI. Agricultura familiar e tecnologia: um estudo de caso do produtor de limão do município de Fernando Prestes. Interface Tecnológica, v.7, n.1, 2010.

PFÜLLER, E. E.; RUFATT, A.; FAVERO, J.; LUPPI，J.; SLONGO, L.; PINHEIRO, S.; CLAMER, S. A.; CAPRINI, T. Diagnóstico dos sistemas de produção e de unidades de Produção agropecuárias do município de Santo Expedito do Sul. Rev. Bras. Agroecologia, v.2, n.1, fev. 2007

TAMDJIAN, J. O.; MENDES, I. L. Geografia Geral e do Brasil: estudos para compreensão do espaço: ensino médio/volume único. São Paulo: FTD, 2005 